\title{
Processos de Significação no Primeiro Ano de Vida
}

\author{
Kátia de Souza Amorim ${ }^{1}$ \\ Faculdade de Filosofia Ciências e Letras de Ribeirão Preto
}

\begin{abstract}
RESUMO - Estudos prévios sugerem indícios de significação em bebês, instigando verificar sua ocorrência. Investigou-se o processo por meio de estudos de caso de bebês (5-12 meses), que frequentavam creche. Foram realizadas entrevistas e videogravações, sendo analisado microgeneticamente com base na Rede de Significações. Mapeou-se, nos vídeos, todos aparecimentos das crianças. Comportamentos que indicassem possíveis processos de significação foram recortados e analisados. Quatro casos são apresentados. Significações (como irritação, pedir/tomar objeto) e recursos de significação (como estender braços, abrir e girar palma da mão) foram considerados coconstruídos desde o nascimento, apesar de nem sempre serem reconhecidos pelos parceiros. No processo, destaca-se o papel da corporeidade. Os resultados desdobram discussões sobre desenvolvimento, abrindo questões que demandam novas incursões e aprofundamentos.
\end{abstract}

Palavras-chave: bebê, significação, linguagem, corporeidade.

\section{Signification Processes in the First Year of Babies' Life}

\begin{abstract}
Former studies suggest evidences of the signification processes of babies, instigating to verify its occurrence. These processes were investigated by case studies of babies (5-12 m.o), attending a daycare center. Empirical data were gathered using interviews and video-tape scenes, which were microgenetically analyzed, based on the Network of Meanings perspective. Behaviors that indicated possible signification processes were selected and analyzed. Four cases are presented. Signification (as irritation, ask for or take an object) and signification means (like stretching the arms, open and spin the palm hand) were verified and considered as co-constructed since birth, though not always recognized by partners. The role of embodiment within the processes is highlighted. Results unfold issues regarding infant development, which demand new research incursions.
\end{abstract}

Keywords: babies, signification, language, embodiment.

Investigações sobre processos de desenvolvimento nos primeiros anos de vida não são novos. Historicamente, o estudo da criança pequena e de suas capacidades comunicativas tem sido realizado a partir de diferentes perspectivas (psicanalítica, etológica, sistêmico-dinâmica, psicobiológica, teoria da atividade, sócio-histórica, teoria da mente, etc.). Inúmeras proposições têm sido elaboradas, cada qual sendo ponto de ancoragem para formas - muitas vezes diversas - de conceber a criança, investigá-la e atuar junto a ela.

Base de muitas dessas investigações está ligada ao mito da criança incompetente e do futurismo. Segundo Carvalho e Beraldo (1989), a ideia é de que a criança - especialmente o recém-nascido - é um organismo incompleto, relativamente incompetente e inadequado, que, por meio de uma série de progressões mais ou menos lineares, vai se tornar um organismo complexo, completo e competente - isto é, um adulto. Acredita-se, ainda, que "a infância é, essencialmente, um período de promessa: seu significado principal reside naquilo que ela virá a ser" (pp. 56-57).

Todavia, a discussão sobre a incompetência e imaturidade tem sido revista. Investigações revelam o bebê equipado já ao nascimento com repertório biológico de grande complexidade e alto grau de organização sensório-motora, perceptual e expressiva (Carvalho, 1998; Fogel, 1993). Tem sido notado que o bebê, mesmo o recém-nascido, tem reações de

1 Endereço para correspondência: USP, Faculdade de Filosofia, Ciências e Letras de Ribeirão Preto; Av. Bandeirantes, 3.900 Monte Alegre. Ribeirão Preto, SP. CEP 14040-901. E-mail: katiamorim@ffclrp.usp.br satisfação diante do rosto humano, sendo capazes de igualar expressões faciais exibidas por outras pessoas (Meltzoff \& Brooks, 2007). Verifica-se reconhecimento e preferência pela voz humana, com alternações vocais do tipo diálogo; e, em torno de dois meses, vocalizações simultâneas e no mesmo tom. Observa-se, ainda, sincronia interacional em que os bebês coordenam a movimentação geral do corpo em ritmo com a fala que ouvem (Trevarthen, 1986, 2005). Ribeiro e Bussab (1998) referem a existência de ecos, espelhos e danças biológicas como canais de comunicação, favorecedores de percepção compartilhada, sincronizações interacionais e contágio emocional. Carvalho e Pedrosa (2003) discutem o envolvimento em ações coordenadas com parceiros desde o nascimento. Segundo essas autoras, o comportamento evoluiria de pré-adaptações para a troca social, a antecipação de ações do outro e a geração de novas modalidades de troca social.

Diversos autores discutem ainda aspectos relacionados à linguagem e aos recursos comunicativos desde o nascimento (Bruner, 1983; Gessel, 2003; Piaget \& Inhelder, 1978). A concepção de comunicação e linguagem, porém, não se mostra consensual, como discutem Carvalho e Pedrosa (2004).

\section{Comunicação e Linguagem nos Primeiros Anos de Vida}

Essa temática não é nova, historicamente perpassando obras de filósofos (Santo Agostinho, citado em Smolka, 
2004), além de pesquisadores da área da psicologia e da linguística. Ela se mostra relacionada a diferentes facetas do desenvolvimento e se encontra imersa em uma série de questionamentos. Em função de perguntas específicas e de pressupostos de base, o tema é explorado a partir de abordagens diversas e, até mesmo, contraditórias (Bruner, 1983; Chomsky, 1986; Piaget \& Inhelder, 1978; Pinker, 2002; Vygotsky, 1991, 1993; Wallon, 1979). Quando os autores se debruçam sobre material empírico, aborda-se a questão a partir de noções de emoção, imitação, expressão, comunicação e significação.

Assim, Lyra (2000), além de Garvey e Silva (2010), a partir de perspectiva sistêmica, tratam a comunicação como compondo as relações que se reorganizam. Lemos (1986) pondera que a linguagem deva ser vista como ação sobre o outro (comunicativo) e sobre o mundo (cognitivo), em que a linguagem da criança altera o universo e é alterada por ele. A linguagem não seria mero reflexo do funcionamento psíquico, mas a própria condição desse funcionamento. Como afirma Smolka (1995), a linguagem não é só meio e modo de (inter/ oper)ação, mas é produto histórico, objetivado; é constitutiva/ constituidora do sujeito (da e na linguagem).

Ao tratar do processo, Schirmer, Fontoura e Nunes (2004) afirmam que, antes de começar a falar, a criança está habilitada a usar olhar, expressão facial e gesto para comunicar-se com os outros, a comunicação sendo não verbal. Para Mendes e Seidl Moura (2009), o bebê começa a perceber e a antecipar comportamentos emocionais do outro e a atribuir-lhes significados. E Galvão (2001), ao tratar de recursos expressivo-emocionais, afirma que o gesto pode exprimir disposições afetivas. Porém, pontua que, embora se constitua em etapa necessária ao acesso à atividade simbólica, a emoção não se confunde com ela, não podendo ser chamada de linguagem.

Buhler, Flabiano, Limongi e Befi-Lopes (2008), Seidl Moura e Ribas (2002) e Meltzoff (1998), apesar de considerarem tempos diferentes no processo, atribuem papel importante à imitação diferida na construção da função semiótica. A partir daquela, a criança se tornaria capaz de diferenciar significantes de significados, começando a utilizar símbolos e signos, expressando-os por meio de gestos, sinais e/ou palavras.

Quanto à relação entre comunicação e linguagem, ela se mostra diversa entre os autores. Alguns deles referem que, nesse primeiro período, verifica-se a ocorrência de protoconversação (Bateson, 1971; Reddy \& Trevarthen, 2004; Trevarthen, 1999; Trevarthen \& Malloch, 2002), quando emergem precursores da linguagem (Silva \& Souza, 2009), em uma comunicação pré-verbal (Meltzoff, Brooks 2007) ou pré-linguística (Bruner, 1983; Mendes \& Seidl Moura, 2004; Papaeliou \& Trevarthen, 2006). Borges e Salomão (2003), no entanto, oscilam em relação a esse posicionamento. Elas afirmam, por um lado, que a linguagem corresponde a uma das habilidades especiais e significativas dos seres humanos, sendo anterior ao surgimento das palavras (do aspecto verbal). Apesar disso, denominam esse período como de protoconversação ou protolinguagem.

Já Rodríguez (2006) questiona estudos com foco em precursores da linguagem, argumentando ser mais produtivo falar em mediação semiótica, dando relevância a outros signos que são bastante utilizados no início das relações do bebê. Nesse sentido, Correia (2009) afirma que atribuir papel protagonístico à linguagem é um dos consensos. $\mathrm{O}$ problema é que o efeito (significado) está sendo atribuído essencialmente às causas visíveis (linguagem), a linguagem sendo apenas a ponta de um "iceberg cognitivo espetacular" (p. 253) que não explica, por si, o processo. A autora destaca então a noção de significação e de construção de significado.

Análise da produção da área evidencia, em alguma medida, o quanto o campo ainda carece de refinamento da terminologia. O ponto não é só que os termos são usados a partir de diferentes referenciais e, portanto, carregam sentidos diversos (polissemia). A questão é que, muitas vezes, os termos são entrelaçados e confundidos entre si, havendo contradição em suas apresentações, possivelmente por limites socioculturais do uso das palavras. Como discute Correia (2009), existem expressões tão comumente utilizadas em nossos discursos, que elas parecem ser bem definidas e operacionalizadas ou gozar de consenso. Porém, isso não se aplica a vários dos conceitos utilizados em cenários psicológicos, como os termos em questão. Dada a diversidade de formas de considerar e abordar a temática, é relevante que se pontue de que lugar esse trabalho parte.

\section{Linguagem e Significação em uma Perspectiva Histórico-Cultural}

A partir de abordagem histórico-cultural, o processo de constituição do sujeito é pensado de modo intrinsecamente articulado ao outro social, imerso na cultura, na linguagem. Tal proposição é frisada pelo fato de que, apesar das suas competências, o bebê humano se revela incapaz de sobreviver sozinho. Nesse sentido, Wallon (citado em Werebe \& Nadel-Brulfert, 1986) afirma que a incompletude do bebê leva à necessidade íntima do outro, da sua assistência constante, o que garante sua própria sobrevivência. É o outro que completa o bebê, compensa-o e o interpreta para o mundo e o mundo para ele. É por meio do outro e dos movimentos deste outro que as atitudes do bebê tomam forma. O ser humano apresentaria assim uma sociabilidade que é biológica. Como refere Wallon, o bebê humano é, antes de mais nada, geneticamente social.

No entanto, segundo Pino (2000), Vygotsky afirma que, além da espécie humana, outras espécies são também dotadas de sociabilidade. O diferencial na espécie humana seria que esta conta com a cultura, por meio da qual o social adquire novas formas de existência. A sociabilidade biológica, sob a ação criadora do ser humano, transforma-se em diferentes modos de organização das relações sociais. O social humano seria assim, ao mesmo tempo, condição e resultado do aparecimento da cultura. É condição porque, sem a sociabilidade natural, a sociabilidade humana seria historicamente impossível, e a emergência da cultura, impensável. É resultado porque as formas de sociabilidade são produções humanas, obras culturais. A sociabilidade humana não seria simplesmente dada pela natureza, mas assumida pelo homem que procura formas de concretizá-la.

Bussab, Pedrosa e Carvalho (2007), a partir da psicoetologia, afirmam também que o neonato é um ser biologicamente organizado para a vida sociocultural. De acordo com Ribeiro e 
Bussab (1998), o homem é, a um só tempo, criatura e criador, a hominização implicando na aptidão natural para a cultura e a aptidão cultural para a natureza. Segundo os autores, excelente evidência da ação da evolução sobre os comportamentos culturais pode ser observada através da linguagem.

Vygotsky (1991) destacou o papel do signo na linguagem e no desenvolvimento humano. Ele afirma que, por meio da interação com os outros sociais, a criança passa a internalizar signos. Estes preenchem a função de criar nova relação entre estímulo e resposta, atuando como instrumento de mediação psicológica. É, então, a internalização do signo e suas características que fazem com que ele tenha função específica de ação reversa (agindo sobre o próprio indivíduo e não só sobre o ambiente), conferindo formas qualitativamente novas à operação psicológica e permitindo ao indivíduo controlar o seu próprio comportamento. O signo seria o próprio meio/modo de articulação das funções, acontecendo graças à linguagem.

Baseada naquele autor, Smolka (2004) especifica propriedades do signo. Segundo ela, o signo é reversível: significa tanto para quem o recebe quanto para quem o emite. O signo opera no campo da consciência, no qual ser autor e espectador constituem atributos de uma mesma pessoa. E o signo atua como elemento mediador, operador e conversor das relações sociais em funções mentais. O signo age, repercute, reverbera como aquilo que se produziu e se estabilizou na história das relações interpessoais.

Nessa discussão, Vygotsky destaca o papel da significação. Como refere Pino (2000), esta confere ao social sua condição humana, expressão da maneira como os seres humanos se organizam e são regidos por leis históricas. Nesse sentido, Smolka (2004) afirma que o que é internalizado é a significação que uma pessoa tem para as outras; o que o outro da relação tem para seu eu; o que, no movimento dialético da relação, dá ao seu eu as coordenadas para saber quem é ele, que posição social ocupa e o que se espera dele. É pelo outro que se constitui em um ser social com sua subjetividade, a significação sendo mediadora universal. E, o portador dessa significação seria o outro, lugar simbólico da humanidade histórica. Para Vygotsky, a significação representaria assim a atividade mais geral e fundamental do ser humano.

Dada a amplitude atribuída ao processo de significação no ser humano, interroga-se se esta poderia ser considerada no caso de bebês. Tal questão se coloca já que estudos empíricos (Amorim, 2004; Fogel, 1993; Vallotton, 2011) têm descrito que o comportamento dos bebês, ao longo do primeiro ano, já se faz de maneira culturalmente adequada, em acordo com as significações do grupo social. Especificamente Amorim, ao estudar processos de adaptação de bebês à creche, verificou que eles modificavam o comportamento de acordo com as diferentes práticas dos adultos (familiares e educadoras). Mesmo bebês bem novos, ao ingressarem na creche - com seus novos significados, interlocutores e novas formas de relações -, agiam de acordo com as novas regras, mantendo formas construídas anteriormente com a família ao mesmo tempo em que negociavam diferentes ações e relações com diferentes interlocutores, em ambos os contextos. O que se concluiu é que, de alguma maneira, o bebê apreendia as significações e as expressava nas suas relações.

Porém, interrogou-se como, nas relações, os bebês lidam com as situações e se posicionam de acordo com diferen- tes significações? Como o bebê, sem ter desenvolvido o sistema de representações, apreende e expressa, age e se relaciona de acordo com significações do grupo (Amorim \& Rossetti-Ferreira, 2008)? Ou, segundo questionamento de Fogel (1993), como bebês, em seus primeiros anos de vida, tornam-se participantes da cultura? Ou, como ele pergunta ainda, se o bebê não obtém informação pelas palavras, que tipo de informação ele está apreendendo e como está apreendendo?

Como afirma Smolka (2004), vale indagar sobre a possibilidade de produção de sentidos, sobre condições de emergência e modos de elaboração, funcionamento e sustentação da significação. Nesse sentido, entre outros autores, tanto Correia (2009) como Bruner (1983) reivindicam o estudo do processo de construção de significados. Para Correia, trata-se de considerar processos na significação, ao falar de significação como vias de acesso ao mundo cultural. Para ela, no entanto, não há pistas sobre como tais processos ocorrem ou como reconhecê-los, do que emerge o problema da indefinição relacionada à sua constituição. Além disso, a autora afirma que as atuais discussões sobre a construção de significados apresentam-se de forma essencialmente teórica, havendo poucos estudos empíricos diretamente relacionados à mesma.

Considerando esses elementos, o objetivo do presente estudo foi investigar processos de significação no primeiro ano de vida. Esse objetivo foi conduzido com base em pressupostos histórico-culturais, já que estes afirmam que ao ser humano é impossível não significar, sendo esta uma característica inerentemente humana. A meta foi então verificar indícios sobre processos de significação do bebê, a partir de suas peculiaridades de desenvolvimento.

A coleta e análise dos dados foi norteada pela Rede de Significações - RedSig (Rossetti-Ferreira, Amorim, Silva \& Carvalho, 2004). Esta conta com pilares teóricos de autores como Bakhtin (1934/1981, 1929/1999), Vygotsky (1991, 1993) e Wallon (citado em Werebe \& Nadel-Brulfert, 1986), sendo uma ferramenta elaborada para a compreensão e para o estudo de processos de desenvolvimento baseado no paradigma da complexidade. A RedSig propõe que o desenvolvimento se dê por meio de processos que ocorrem nas e por meio das múltiplas interações estabelecidas pelas pessoas, em contextos social e culturalmente organizados. As pessoas são concebidas como imersas em, constituídas por e submetidas a uma malha de elementos de natureza semiótica. Aspectos das pessoas em interação e dos contextos específicos são considerados como inseparáveis em processos de mútua constituição.

Ao se utilizar dessa perspectiva, a meta é apreender vários dos elementos presentes nas situações e acompanhar os movimentos de emergência, deslizamento e transformação dos processos de desenvolvimento. Importante eixo norteador é a busca por capturar o processo de transformação e mudança, ao longo do tempo e das situações (Rossetti-Ferreira, Amorim, Silva \& Carvalho, 2008).

Como afirma Bussab (2000), a compreensão da complexidade deve se dar através de um exercício de rigor metodológico, em que se produza um procedimento que explicite com clareza suas questões. Com base nessas considerações, passa-se a apresentar a condução da pesquisa que se deu a partir de estudos de caso múltiplos. 


\section{Método}

O estudo de caso (Yin, 2005) representa uma estratégia de investigação em função do tipo de questão de pesquisa - se e como determinado evento ocorre. No caso da presente pesquisa, se e como ocorre o processo de significação no bebê.

Ele é usado, ainda, para o estudo de processos marcados pela complexidade, em que se busca preservar características dos eventos dentro de seus contextos e relações. Finalmente, por entender que se parte de hipótese - de que bebês, mesmo antes da aquisição da linguagem verbal, já significam - em que a questão trava um diálogo tenso com a literatura. A pesquisa impõe, assim, a realização de estudos exploratórios, marca dos estudos de caso.

Antes de conduzi-los, no entanto, o projeto foi submetido e aprovado pelo Comitê de Ética de instituição de ensino superior; ainda, foi realizado norteado pelos preceitos da Resolução 196/96 do CNS. A participação das crianças no estudo foi feita com consentimento das famílias, inclusive para a apresentação das imagens.

\section{Participantes}

A investigação utilizou o banco de dados do projeto "Processos de adaptação de bebês à creche". Este acompanhou 21 bebês (4-13 meses), suas famílias, educadoras e técnicas, após o ingresso dos bebês em uma creche universitária. À época, os bebês foram subdivididos em subgrupos, a depender das idades e habilidades. $\mathrm{O}$ ambiente em que eles permaneciam era organizado de modo a que as crianças permanecessem sentadas ou engatinhando, no chão ou em colchões, onde brinquedos e material lúdico ficavam disponibilizados. Essa organização possibilitava ainda que os bebês se mantivessem muito próximos uns dos outros, estabelecendo processos interativos.

Dos 21 bebês, sete foram selecionados aleatoriamente para os estudos de caso. São eles: Nisete (5 meses), Túlio (6 meses), Linda (9 meses), Vera (10 meses), Isa (11 meses), Armando (11 meses) e Vitor (12 meses). Além deles, as famílias, as educadoras e as técnicas da creche foram também consideradas enquanto sujeitos participantes.

\section{Procedimentos de coleta e análise de dados}

Para a condução do projeto geral, foram realizados vários registros da situação de adaptação e frequência à creche. Dentre eles, entrevistas e videogravações, as quais foram utilizadas no presente estudo. As entrevistas semiestruturadas foram realizadas quinzenalmente com as mães, além de educadoras e técnicas (psicóloga, nutricionista, auxiliar de enfermagem), para apreender concepções sobre bebês e percepção dos processos de adaptação e desenvolvimento na creche.

As videogravações foram realizadas nos três primeiros meses de frequência, sendo diárias e guiadas por objetivos como reações e interações da criança com familiares, outras crianças e educadoras, além de apresentação/mediação do ambiente, dos objetos e das pessoas aos bebês. As gravações duravam em média três horas diárias (manhã, almoço e final da tarde), tendo resultado em um arquivo de 54 fitas de vídeo.

A construção do corpus foi feita articulando-se falas das entrevistas com cenas das videogravações. A transcrição das cenas foi feita individualmente por criança, no programa Excel, onde se tabulou todos os aparecimentos em ordem cronológica, descrevendo-se a minutagem ${ }^{2}$, tempo e quais pessoas estavam presentes; ainda, se a criança manipulava objeto, quais eram as ações da(s) criança(s) e do(s) adulto(s), além de expressões faciais, olhares e falas/balbucios/vocalizações dos sujeitos envolvidos. A tabulação buscou, ainda, descrever a concomitância dos eventos e sua sequência.

A partir da leitura do material, em contínua observação das videogravações, buscou-se apreender nas peculiaridades do bebê (gestos, emoções, expressividade, posturas corporais), nas situadas relações com os parceiros sociais, elementos que pudessem ser sinalizadores de processos de significação. Como discute Guimarães (2008), isso significou perguntar sobre as qualidades da ação, gesto, sentidos, emoção, relação com os objetos e com os parceiros. Implicou em enfocar a significação nas negociações, na qualidade comunicativa dos gestos e nas formas relacionais mediadas por objetos. No estudo, dentre outros, buscou-se acompanhar a ocorrência de significações na separação mãe/bebê (despedida - "tchau"); ou, ligada ao uso de objetos (como telefone) e às ações a serem realizadas pela criança (como mamar). Ainda, foram analisadas significações por meio das formas de relações com outras crianças, como "bater/acariciar", dar/pegar ou "roubar/ tomar" o objeto do outro. Parte do sistema sinalizador, essas formas fornecem pistas sobre atitudes com relação à própria criança e às outras pessoas; permitem focalizar aspectos intersubjetivos e dialógicos, destacando-se práticas sociais e suas condições. Como discutem Brannigan e Humphries (1972), por meio deles, a meta é apreender circunstâncias em que comportamentos ocorrem, pois é nessa configuração que o comportamento contém significado.

Tais aspectos orientaram a escolha dos episódios a serem pormenorizadamente analisados e levou aos recortes que possibilitaram apreender indícios sobre significação em bebês. Para o presente artigo, dos sete estudos de caso conduzidos, serão apresentados dados de quatro deles: de Túlio, Linda, Isa e Armando. Essa seleção se fez em função da pergunta aqui colocada, de modo a substanciar o diálogo entre o material empírico e as questões teóricas.

\section{Resultados}

\section{Caso 1}

Linda contava com nove meses ao ingresso na creche. Para a educadora Mirtes, Linda é "muito concentrada. Sempre sozinha, na dela. (...) Ela não é de chorar. (...) É mais

2 De acordo com o Dicionário Aulete (2011), minutagem significa registrar as cenas de um vídeo, minuto a minuto, para facilitar a localização de cenas a posteriori. Segundo o Dicionário Michaelis (2011), a minutagem significa a cronometragem, em minutos, de uma cena de cinema, de teatro etc. 
reticente. Cê tem que observar muito ela pra poder captar alguma coisa".

Essa percepção do comportamento da criança é compartilhada pela psicóloga, que afirma: "A Linda é uma criança assim... diferente (...) Isso me chama muita atenção... e me preocupa, inclusive. Porque eu acho até melhor que a criança chore, que descabele, mas que depois ela acalma e entra em interação, do que uma criança que aparentemente tá tudo bem. Então, não sei... A gente tá observando..”.

Só algumas semanas depois, quando Linda chora ou vocaliza irritada, é que ela passa a ser vista como alguém que se posiciona frente a contrariedades. Como diz a educadora: "A Linda agora é uma criança, não é mais uma boneca. ... Antes, ela ficava quietinha, bonitinha. Se fizesse xixi ou cocô, ela não reclamava... Agora, não! Pra comer, ela bate a mão se você não dá logo a comida. ... Ela manifesta mesmo no que ela quer... A mãe tava falando 'Ela era tão quietinha!'. Eu falei, "Ela era!!"”.

Apesar dessas percepções sobre a inicial baixa expressividade de Linda, verificou-se, ao vídeo, que a criança reiteradamente expressava uma série de manifestações que transmitiam irritação/contrariedade (especificamente, através do gesto de coçar a nuca) (Rodrigues \& Amorim, 2008). Apesar dessas manifestações, para a mãe e as educadoras, este seu gesto não expressava significações. Assim, ao coçar da nuca, elas retiravam a mão da criança do pescoço. Ao não reconhecer esse comportamento como uma reação a incômodos e, à época, por a criança não apresentar outros comportamentos dentro dos (re)conhecidos padrões culturais, os adultos passaram a interrogar a própria competência expressiva da criança. Portanto, a análise do caso revela que a criança apresentava comportamentos significativos sem que fossem percebidos/reconhecidos como prenhes de significado; ao gesto não era atribuído significação, por mais presente nas situações.

\section{Caso 2}

Este se refere ao bebê Túlio e à construção de seu gesto de levantar os braços para ir ao colo da mãe. Na primeira cena destacada, na Figura 1, Túlio está com sete meses e meio e se encontra sentado no carrinho. Quando ele vê a mãe, ele sorri largamente e movimenta desordenadamente os braços para cima, para baixo e para os lados, olhando diretamente para o rosto dela. Esta se aproxima e passa a soltar o filho do carrinho enquanto fala com ele. Ele sorri e agita mais ainda os braços de forma desordenada. Quando a mãe diz "Vamos!", ele sorri, mantendo os braços parados e abaixados, sem levantá-los para ir ao colo da mãe. Ela pega, então, braço após braço, levantando-os, para depois pegá-lo no colo.

Numa segunda cena (retratada na Figura 2), quinze dias após, vê-se novamente Túlio sentado no carrinho. Quando a mãe se aproxima do filho, ele sorri largamente. Daí, ele estica longamente o braço direito e o corpo na direção da mãe. A mãe abaixa-se para retirar o cinto de proteção e fala com ele. Enquanto ela fala, ele balbucia, levantando e esticando o braço na direção da mãe. Quando ela termina de soltar o cinto e vai pegá-lo, ele levanta simultaneamente os dois braços em sua direção.

\section{Caso 3}

Esse terceiro caso envolve dois bebês: Túlio (6 meses) em seu processo de sentar-se e Linda (9 meses) aprendendo a engatinhar. Nos dois casos, em função de um conjunto de concepções e expectativas que demarcam os tempos de desenvolvimento, há uma hipótese inicial de atraso no desenvolvimento. Túlio não se senta (nem com apoio) e Linda não engatinha (apesar de bebês bem mais novos já o fazerem). Em função da hipótese de atraso, educadoras e

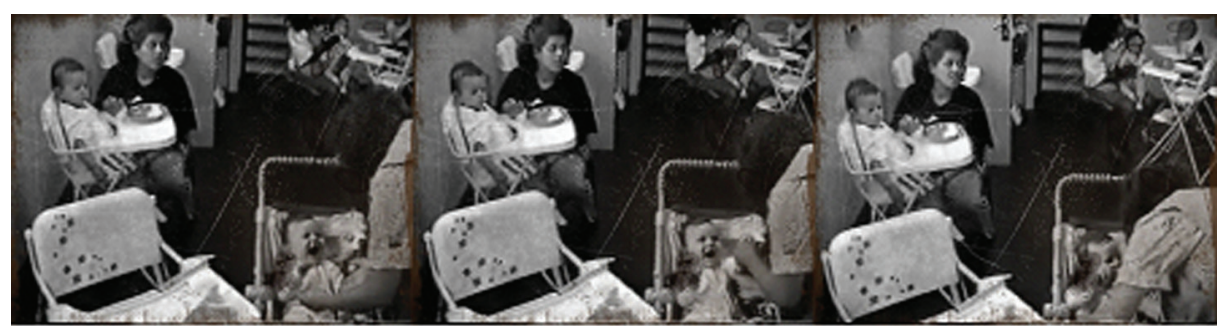

Figura 1. Túlio não ergue os braços para ir ao colo da mãe.

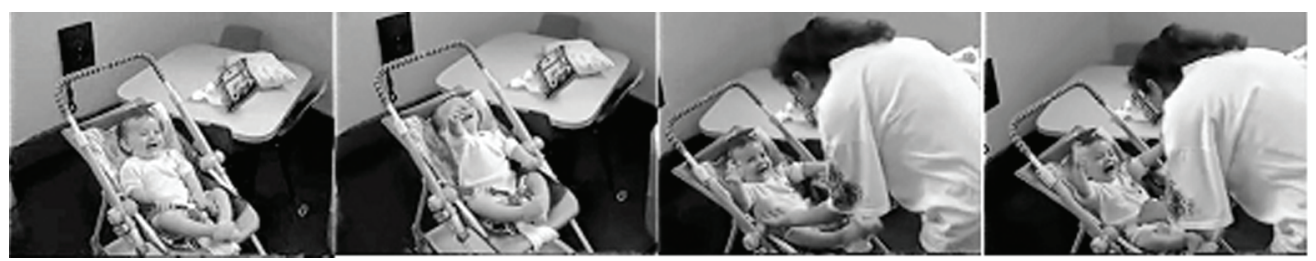

Figura 2. Túlio ergue os braços para ir ao colo da mãe. 
famílias passam a fazer investimento junto às crianças. No caso de Túlio, as educadoras passam a colocá-lo sentado no colchonete, amparado por almofadas; ou, sentado em seus colos ou no cadeirão. No caso de Linda, as educadoras e a mãe passam a colocá-la repetidamente na posição de engatinhar, concretamente moldando seu corpo nessa posição. Buscam, ainda, estimular a criança a efetuar o deslocamento, mediante ações que provoquem a imitação ou que mobilizem emocionalmente a criança de modo a que ela busque se aproximar dos adultos. Em ambos os casos, as cenas indicam rápida transformação: Túlio senta-se sem apoio e Linda passa a engatinhar com firmeza e agilidade.

\section{Caso 4}

O último estudo de caso a ser aqui apresentado envolve os bebês Isa e Armando, irmãos gêmeos de 11 meses de idade. (ver Figura 3) Na cena, Isa e Armando são colocados no chão, frente a frente. Ao ser sentada, Isa pega um cilindro próximo a ela. Assim que o irmão a olha, ele dirige corpo e mãos na direção da irmã, pegando o cilindro da mão dela, sem dar chances de ela pegá-lo de volta. Inicialmente, Isa choraminga. Depois de alguns segundos sem mudanças na situação, ela para de chorar e olha para as mãos de Armando e para o cilindro. Ela olha então diretamente para o rosto dele, enquanto estende a mão esquerda na sua direção, com a palma virada para cima, permanecendo assim estendida por alguns segundos. Armando vê a irmã e transfere o cilindro da mão esquerda para a direita. Depois, segura-o com as duas mãos. Isa fica com uma expressividade muito séria. Ela apoia, então, a mão esquerda no colchão e leva a mão direita na direção do irmão, agora sua mão estando com a palma virada para baixo. A mão de Isa se desloca até o cilindro até quase tocá-lo. Sem conseguir pegá-lo, ela volta o corpo para trás. Volta a chorar e a olhar na direção da mãe (Costa \& Amorim, 2010).

\section{Discussão}

Para iniciar a discussão dos casos, resgata-se Vygotsky (1991), para quem o gesto só se torna um gesto verdadeiro após manifestar, objetivamente para os outros, suas funções e ser entendido pelos outros como tal. Mas, ao se analisar o caso de Linda, de coçar a nuca, pode-se dizer que, pelo fato de o gesto não ser reconhecido pelos adultos, a criança não apresenta formas/modos de significar? Ela não está significando porque o significado não é compartilhado? Interroga-se, a partir daí, o que quer dizer significar quando se considera bebês. O significado é habilitado somente quando ele faz sentido para o outro? Ou, como nesse caso, a significação apenas não era compreendida em função dos modos de a criança expressar sua irritação? Essas questões devem ser formuladas, pois, como discute Galvão (2001), nos primeiros meses de vida, o adulto interpreta o significado das expressões do bebê, conforme seus valores, costumes e expectativas, sendo levado a agir de acordo com os parâmetros culturais e crenças.

Além disso, considerando-se que houve recusa do gesto do coçar, associada a uma valorização de outras manifestações expressivas, é possível dizer que a ação da criança, nas relações sociais, não criou nada? A recusa do gesto como significativo não foi reversível à criança, já que Linda acabou por utilizar novos meios/recursos de agir que fossem (re) conhecidos pelos parceiros de interação? Seu comportamento não criou novas formas de processos enraizados na cultura? A significação de Linda não teria a ver com suas relações que, em curtíssimo tempo, levou a criança a modificar sua forma de se expressar, de modo a ser reconhecida como alguém que significa? No movimento dialético da relação, por meio do gesto, não estariam sendo construídas as coordenadas para Linda saber quem é ela, a posição social que ocupa e o que se espera dela? O que está em questão não é exatamente a significação que o outro da relação tem para seu eu, no sentido de constituição de um ser social com sua subjetividade (identificada pelo outro)?

Correia (2009) afirma, ao discutir questões semelhantes, que se deduz que existe a produção de significados para si e o compartilhar de significados que envolve um "outro". A direção que a construção de significados pode assumir, então, depende da interação com um outro. Envolve o outro mesmo depois de ser significado para o próprio indivíduo, pois só será útil se puder ser compartilhado.

No entanto, o ponto é: apesar desse movimento em direção ao outro, como não considerar os gestos e comportamentos carregados de significações, mesmo quando não reconhecidos pelo outro? Como não reconhecer o processo de significação, se Smolka (2004) afirma que é impossível ao ser humano não significar, a significação fazendo parte da atividade humana? Assim, faríamos a pergunta inversa: seria possível ao bebê não significar se, como a autora defende, a possibilidade de significação não existe apenas como capacidade intrinsecamente humana, mas como condição daquilo que é especificamente humano? Ou, ao se afirmar que o processo cultural e de significação se inicia com a aquisição do signo verbal, não estaria havendo uma confusão entre signo e materialidades do signo? Confusão entre linguagem e língua, entre signo e palavra? Assim, se significar é inerentemente humano e o signo tem diversas materialidades, ao se estudar o bebê, não se deveria tratar da significação para além da

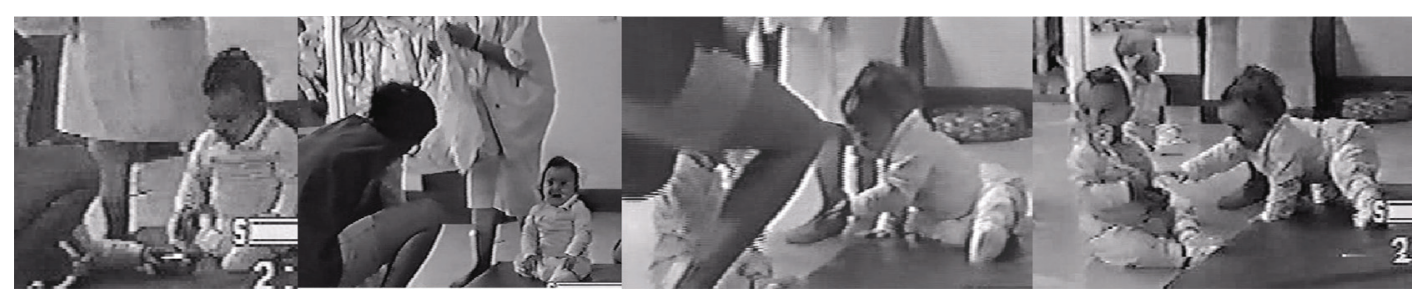

Figura 3. Invertendo a posição da mão - os gestos de pedir e tomar. 
palavra? Para esse impasse, o próprio Vygotsky aponta um caminho: a ação.

Em seu livro, Vygotsky (1993) trata de processos do desenvolvimento da fala e do pensamento no primeiro ano de vida. Nele, infere-se que a ação é a base para o desenvolvimento dessas funções. Essa inferência parte de sua abordagem da frase bíblica "No princípio era o Verbo" e a sua crítica a "Goethe que faz Fausto responder: "No princípio era a Ação". Vygotsky afirma entender que o objetivo desta última frase é diminuir o valor das palavras, as quais são consideradas por ele como signo máximo. Porém, ele aceita essa versão, se enfatizada de outra forma: “a ação já existia antes dela; a palavra é o final do desenvolvimento, o coroamento da ação" ( p. 131).

Nessa perspectiva, Vygotsky (1991) propõe que o gesto de apontar representa o primeiro estágio do desenvolvimento da fala humana, transição da expressão afetiva pura em direção à linguagem objetiva. Ele e outros autores discutem que a análise do gesto de apontar mostra a mudança realizada na orientação da ação da criança, para o outro e para si. O movimento, afetado pela interpretação do outro, converte-se em meio de relação. Como descreve Vygotsky, "Quando a mãe vem em ajuda da criança, e nota que o seu movimento indica alguma coisa, a situação muda fundamentalmente. $\mathrm{O}$ apontar torna-se um gesto para os outros" (1991, p. 63). Porém, isso quer dizer que o significado só é construído quando o adulto e a cultura são respondentes às ações da criança?

No entanto, se na perspectiva histórico-cultural o foco se faz dentro da noção de dialogismo, como fazer um recorte a partir da criança (cujo gesto incompleto de pegar leva ao apontar) e só daí observarmos o parceiro (que interpreta o gesto e reage a ele)? Não se deveria, ao contrário, deslocar o olhar do processo/criança para apreendê-lo nas interações com parceiros, acompanhando suas construções conjuntas? Essa ampliação do olhar é entendida como fundamental, pois, como discute Leiman (2002), temos que buscar a linguagem na mútua responsividade, sendo necessária a linguagem que resgate o outro em relação ao qual a posição de um se coloca.

Mais ainda, como interroga Guimarães (2008), existiria antes do movimento de apontar outros mecanismos que, sem exigir a funcionalidade motora do apontar, poderiam desempenhar um papel equivalente? Ou seja, antes da existência da funcionalidade motora, seria possível falar já de uma atividade cultural?

Essa foi a perspectiva que se lançou ao caso de Túlio estender os braços para ir ao colo da mãe. A partir desse episódio, em acordo com Lock (1979), discute-se que ninguém nasce, por exemplo, com a habilidade para levantar os braços de modo a ajudar o outro a pegá-lo. Nas primeiras ocorrências dessa atividade, os braços da criança somente tornam-se levantados pela ação do outro, que põe suas mãos sob os braços da criança. Inicialmente, não há ajustamento a esse comportamento. Porém, ser pego no colo ocorre no contexto cotidiano dos bebês para serem alimentados, lavados, confortados, atividades essas que ocupam ampla parte do dia. A criança torna-se familiar com o ato e começa a reconhecer as ações direcionadas a ela. Ela passa, então, a antecipar e erguer os braços na direção do adulto. Se, inicialmente, o bebê respondia à estimulação física, passa depois a se ajustar às posições e, inclusive, a requerê-las.
A discussão coloca em foco que o gesto (como estender os braços para ir ao colo ou sentar-se e engatinhar) não é construído a partir de significações do adulto, parceiro de interação, após a realização ao acaso do gesto pela criança. Os casos indicam que representam uma coconstrução dos parceiros nos repetidos eventos interativos. Os gestos e as posturas são moldados, coconstruídos e significados de forma mediada na relação com o adulto, na sua mútua responsividade, dentro de práticas sociais.

Nesse sentido, ações consideradas básicas como estender braços, sentar-se e engatinhar mostram-se carregadas de significados culturais, representando em si significações. Eles representam a materialização de significações culturais, constituídas por meio de múltiplos diálogos sem palavras dos adultos com as crianças, diálogo este atravessado por uma infinidade de palavras, com sua história, concepções e práticas.

Pelo apresentado, em diálogo com a abordagem histórico-cultural, teoricamente, o ser humano participa de modo inescapável das significações. Dos casos analisados, essa significação se faz pela ação, não ocorrendo somente quando compreendida pelo adulto e nem somente em resposta do adulto ao gesto da criança. Se um bebê significa pela ação, isso leva a considerar o papel da corporeidade como mediador semiótico, destacando-se sua centralidade dentro de processos relacionais. De maneira semelhante, Guimarães (2008) afirma que o corpo constitui o primeiro circuito de comunicação das crianças com os outros, o corpo representando espaço de construção simbólica e cultural na relação.

$\mathrm{Na}$ corporeidade, destaca-se seu caráter simultaneamente público e privado, a corporeidade sendo estruturada em relação à alteridade pelo fato de, na relação, a experiência ser simultaneamente ativa e passiva, dual, recíproca. Como Coelho Jr. (2003) menciona na conclusão de seu artigo, há uma intercorporeidade que "exige um inevitável encontro com a radical alteridade do outro", havendo permanente reversibilidade entre as pessoas.

Para Soffer (2001), esse caráter experiencial se encontra incrustado em aspectos biológicos, psicológicos e do contexto cultural, tendo caráter histórico. Na história relacional, em função das concepções sociais, as experiências adquirem significados. Ainda, a percepção-ação corporificada representaria um nível mais fundamental do que o do enunciado linguístico, porque ela já está estruturada como alteridade em relação à comunidade, requerendo conceituação de social mais imediata, íntima e integral. O significado como percepção corporificada é visto assim como mais radicalmente aberto à cultura, estando pronto para ser encontrado, moldado e remoldado na experiência.

A significação encontra-se, assim, aquém das palavras (apesar de atravessada por elas). Estender braços para ir ao colo, sentar-se, engatinhar e outros representam a corporificação de práticas culturais, a corporificação de significados sociais. O corpo é significado e significa. Nessa linha, o significado não é criado por manipulação abstrata de símbolos. O significado deriva da correlação com as coisas, a partir da experiência corporificada no mundo. Como Costall (1995) afirma, o significado não representa adição psíquica, mas algo que existe na relação ser humano - ambiente.

Esses posicionamentos não são vistos como carregando oposição básica com as ideias do referencial histórico-cultu- 
ral. A própria Smolka (2004) menciona o corpo como lócus de significação e constituição do sujeito: corpo marcado destacado, nomeado, constituído como tal - pela linguagem; corpo com estatuto de sujeito que se vê, se (re)conhece. Corpo marcado, afetado pelas práticas historicamente construídas.

Tais práticas construídas se concretizam nos gestos de Isa de estender braços e mãos, gestos estes carregados de significações. A depender da simples mudança da posição da palma da mão - virada para cima ou para baixo - o gesto se transforma radicalmente: passa de um pedido pelo objeto (palma da mão virada para cima, com olhar de requisição), para a busca por tomar o objeto (palma da mão virada para baixo, a face carregada de expressão de irritação). Vale destacar ainda que esse gesto é dirigido a um parceiro de idade - e não a um adulto - em um diálogo mudo entre bebês.

Resumindo as questões abordadas nesse texto, o pressuposto é de que o bebê humano é um ser da linguagem, a ele não sendo possível não significar. Nesse sentido, com base em estudos anteriores, conduziram-se novos estudos empíricos, de modo a se verificar se o bebê apresenta processos que se possa conceber como de significação.

Verificou-se, nos estudos de caso, que a significação ocorre, mesmo quando o parceiro social não reconhece, pois o que está em questão não é a língua, mas a linguagem em seu sentido mais amplo. Ainda, a significação não emerge a partir de respostas do adulto a gestos e comportamentos ao acaso do bebê. A significação é, sim, coconstruída nas relações em contextos situados, com a participação de ambos os parceiros em sua mútua responsividade. A significação se faz ainda a partir das peculiaridades de recursos do bebê, a significação sendo apreendida/expressa por meio de sua corporeidade. Apesar das evidências dos processos de significação nos bebês, não se tem ainda suporte para discuti-los em termos de uso de signos.

No percurso da investigação sobre linguagem, comunicação e significação de bebês, o estudo estruturou-se em diálogo com o referencial histórico-cultural. Simultaneamente, a pesquisa mantém esse suporte, os achados e as reflexões servindo de contrapontos, questionamentos e pontuações em sua elaboração, construídas a partir de espaços abertos existentes dentro do próprio referencial. O diálogo entre teórico e empírico resultou na emergência de vários aspectos que podem permitir lançar novos olhares e práticas aos processos de desenvolvimento da criança no primeiro ano de vida. Porém, várias questões ainda são consideradas como devendo ser futuramente aprofundadas.

\section{Referências}

Amorim, K. S., \& Rossetti-Ferreira, M. C. (2004). A matriz sóciohistórica. In M. C. Rossetti-Ferreira, K. S.Amorim, A. P. S. Silva, \& A. M. A. Carvalho. (Eds.), Rede de Significações e o estudo do desenvolvimento humano (pp. 94-112). Porto Alegre: Artmed.

Amorim, K. S., \& Rossetti-Ferreira, M. C. (2008). Corporeidade, significação e o primeiro ano de vida. Arquivos Brasileiros de Psicologia, 60, 67-81.
Aulete (2011). IDicionário. Retrieved from http://aulete.uol.com. $\mathrm{br} /$ site.php?mdl=aulete_digital\&op=loadVerbete\&pesquisa $=$ 1\&palavra $=$ minutagem.

Bakhtin, M. (1981). The dialogical imagination. Four essays. Austin: University of Texas Press. (Trabalho original publicado em 1934)

Bakhtin, M. (1999). Marxismo e filosofia da linguagem. São Paulo: HUCITEC. (Trabalho original publicado em 1929).

Bateson, M. C. (1971). The interpersonal context of infant vocalization. Quarterly Progress Report of the Research Laboratory of Electronics, 100, 170-176.

Borges, L. C., \& Salomão, N. M. R. (2003). Aquisição da linguagem: Considerações da perspectiva da Interação Social. Psicologia: Reflexão \& Crítica, 16(2), 327-336.

Brannigan, C. R., \& Humphries, D. A. (1972). Human nonverbal behavior, a means of communication. In N. G. Blurton Jones (Ed.), Ethological studies of child behavior (pp. 37-64). Cambridge: Cambridge University Press.

Bruner, J. (1983). Child's talk: Learning to use language. New York: Norton.

Buhler, K. E. B., Flabiano, F. C., Limongi, S. C. O., \& Befi-Lopes, D. M. (2008). Protocolo para observação do desenvolvimento cognitivo e de linguagem expressiva. Revista da Sociedade Brasileira de Fonoaudiologia, 13(1), 60-68.

Bussab, V. S. R. (2000). Fatores hereditários e ambientais no desenvolvimento: a adoção de uma perspectiva interacionista. Psicologia Reflexão e Crítica, 13, 223-243.

Bussab, V. S. R., Pedrosa, M. I., \& Carvalho, A. M .A. (2007). Encontros com o outro: empatia e intersubjetividade no primeiro ano de vida. Psicologia USP, 18(2), 99-133.

Carvalho, A. M. A. (1998). Etologia e comportamento social. In L. Souza, M. F. Q. Freitas, \& M. M. P. Rodrigues (Eds.), Psicologia: reflexões (im)pertinentes (pp. 195-224). São Paulo: Casa do Psicólogo.

Carvalho, A. M. A., \& Beraldo, K. E. A. (1989). Interação criançacriança: ressurgimento de uma área de pesquisa e suas perspectivas. Cadernos de Pesquisa, 71, 55-61.

Carvalho, A. M. A., \& Pedrosa, M. I. (2003). Precursores filogenéticos e ontogenéticos da linguagem: reflexões preliminares. Revista de Ciências Humanas, 34, 219-252.

Carvalho, A. M. A., \& Pedrosa, M. I. (2004). Communication in early infancy: Some reflections from an evolutionary perspective. In A. U. Branco \& J. Valsiner (Eds.), Communication and metacommunication in human development (pp. 83-103). Greenwich, CT: Information Age Publishing.

Chomsky, N. (1986). Knowledge of language. New York: Praeger.

Coelho Jr., N. E. (2003). Da intersubjetividade à intercorporeidade. Contribuições da filosofia fenomenológica ao estudo psicológico da alteridade. Psicologia da USP, 14(1), 185-209.

Correia, M. F. B. (2009). Indeterminação, multidimensionalidade e relevância do processo de construção de significados. Psicologia em Estudo, 14, 251-258

Costa, C. A., \& Amorim, K. S. (2010, Setembro). A abreviação de significações nas relações de bebês no primeiro ano de vida. Trabalho apresentado no III Congresso Brasileiro Psicologia: Ciência e Profissão, São Paulo.

Costall, A. (1995). Socializing affordances. Theory \& Psychology, 5(4), 467-481. 
Fogel, A. (1993). Developing through relationships: Origins of communication, self and culture. Hertfordshire: Harvester Wheatsheaf.

Galvão, I. (2001). Expressividade e emoção: ampliando o olhar sobre as interações sociais. Revista Paulista de Educação Física, supl.4, 15-31.

Garvey, A., \& Silva, M. (2010). Desenvolvimento da comunicação, identidade e emoções na infância: contribuições das perspectivas relacional e dialógica. Educar, 36, 55-64.

Gessel, A. (2003). A criança dos 0 aos 5 anos ( $3^{\mathrm{a}}$ ed.) São Paulo: Martins Fontes.

Guimarães, D. (2008). Entre gestos e palavras: pistas para a educação das crianças de 0 a 3 anos. Retrieved from http:// www.maxwell.lambda.ele.puc-rio.br/13586/ 13586. PDF.

Leiman, M. (2002). Toward semiotic dialogism. The role of sign mediation in the dialogical self. Theory \& Psychology, 12(2), 221-235.

Lemos, C. T. G. (1986). Interacionismo e aquisição de linguagem. DELTA, 22, 231-248.

Lock, A. (1979). Action, gesture and symbol: The emergence of language. London: Academic Press.

Lyra, M. C. D. P. (2000). Desenvolvimento de um sistema de relações historicamente construído: contribuições da comunicação no início da vida. Psicologia: Reflexão e Crítica, 13, 257-268.

Meltzoff, A. N., \& Brooks, R. (2007). Intersubjectivity before language: Three windows on preverbal sharing. In $\mathrm{S}$. Bråten (Ed.), On being moved: From mirror neurons to empathy (pp. 149-174). Philadelphia, PA: John Benjamins.

Meltzoff, A. N. (1998). Imitation, objects, tools, and the rudiments of language in human ontogeny. Human Evolution, 3(1,2), 45-64.

Mendes, D. M. L. F., \& Seidl Moura, M. L. (2004). Desenvolvimento da brincadeira e linguagem em bebês de 20 meses. Psicologia Teoria e Pesquisa, 20, 215-222.

Mendes, D. M. L. F., \& Seidl Moura, M. L. (2009). Expressões faciais de emoção em bebês: importância e evidências. Estudos de Psicologia, 9, 307-327.

Michaelis (2011). Moderno Dicionário da Língua Portuguesa. Retrieved from: http://michaelis.uol.com. $\mathrm{br} /$ moderno/portugues/index.php?lingua=portuguesportugues\&palavra=MINUTAGEM.

Papaeliou, C. F., \& Trevarthen, C. (2006). Prelinguistic pitch patterns expressing 'communication' and 'apprehension'. Journal of Child Language, 33, 163-178

Piaget, J., \& Inhelder, B. (1978). A psicologia da criança. Rio de Janeiro: Difel.

Pinker, S. (2002). O instinto da linguagem: como a mente cria a linguagem. São Paulo: Martins Fontes.

Pino, A. (2000). O social e o cultural na obra de Vigotski. Educação e Sociedade, 71, 45-78.

Reddy, V., \& Trevarthen, C. (2004). What we learn about babies from engaging with their emotions. Zero to Three, 24(3), 9-15.

Ribeiro, F. L., \& Bussab, V. S. R. (1998). Biologicamente cultural. In L. Souza, M. F. Q. Freitas, \& M. M. P. Rodrigues (Eds.), Psicologia: reflexões (im) pertinentes (pp. 177-203). São Paulo: Casa do psicólogo.

Rodríguez, C. (2006). Del ritmo al símbolo. Los signos en el nacimiento de la inteligência: Cuadernos de Educación. Barcelona: Universitat de Barcelona.
Rodrigues, L. A., \& Amorim, K. S. (2008, Outubro). Como os bebês se posicionam e são posicionados enquanto sujeitos da linguagem? Trabalho apresentado na XXXVIII Reunião Anual de Psicologia, Uberlândia.

Rossetti-Ferreira, M. C., Amorim, K. S., Silva, A. P. S., \& Carvalho, A. M. A. (Eds.), (2004). Rede de Significações e o estudo do desenvolvimento humano. Porto Alegre: Artmed.

Rossetti-Ferreira, M. C., Amorim, K. S., Silva, A. P. S., \& Oliveira, Z. M. R. (2008). Desafios metodológicos na perspectiva da Rede de Significações. Cadernos de Pesquisa, 38, 147-170.

Seidl Moura, M. L., \& Ribas, A. F. P. (2002). Imitação e desenvolvimento inicial: evidências empíricas, explicações e implicações teóricas. Estudos de Psicologia (Natal) 7, 207-215.

Silva, F. T. N., \& Souza, C. B. A. (2009). Discriminação simples com mudanças sucessivas na função dos estímulos: aprendizagem em bebês. Psicologia Teoria e Pesquisa, 25, 569-580.

Smolka, A. L. B. (1995). A concepção de linguagem como instrumento: um questionamento sobre práticas discursivas e educação formal Temas em Psicologia, 2, 11-21.

Smolka, A. L. B. (2004). Sobre significação e sentido: uma contribuição à proposta da Rede de Significações. In M. C. Rossetti-Ferreira, K. S. Amorim, A. P. S. Silva, \& A. M. A. Carvalho (Eds.), Rede de Significações e o estudo do desenvolvimento humano (pp. 35-50). Porto Alegre: Artmed.

Soffer, J. (2001). Embodied perception. Theory \& Psychology, $11(5), 655-670$.

Schirmer, C. R., Fontoura, D. R., \& Nunes, M. L. (2004). Distúrbios da aquisição da linguagem e da aprendizagem. Jornal de Pediatria, 80(2), 95-103.

Trevarthen, C. (1986). Form, significance and psychological potential of hand gestures of infants. In J. L. Nespoulous, P. Perron, \& A. R. Lecours (Eds.), The biological foundation (pp. 149-202). Hillsdale, NJ: Erlbaum.

Trevarthen, C. (1999). Intersubjectivity. In R. Wilson \& F. Keil (Eds.), The MIT encyclopedia of cognitive sciences (pp. 413416). Cambridge: MIT Press.

Trevarthen, C. (2005). First things first: Infants make good use of the sympathetic rhythm of imitation, without reason or language. Journal of Child Psychotherapy, 31, 91 - 113.

Trevarthen, C., \& Malloch, S. (2002). Musicality and music before three: Human vitality and invention shared with pride. Zero to Three, 23(1), 10-18.

Vallotton, C. (2011). Babies open our minds to their minds: how listening to infant signs complements and extends our knowledge of infants and their development. Infant Mental Health Journal, 32(1), 115-133.

Vygotsky, L. S. (1991). A formação social da mente. São Paulo: Martins Fontes.

Vygotsky, L. S. (1993). Pensamento e linguagem. São Paulo: Martins Fontes.

Wallon, H. (1979). Do ato ao pensamento. Lisboa: Moraes Editora

Yin, R. (2005). Estudo de caso: planejamento e métodos (3a . ed.) Porto Alegre: Bookman.

Recebido em 11.09.2009

Primeira decisão editorial em 27.01.2011

Versão final em 09.11.2011

Aceito em 28.11.2011 